\title{
Übersicht über die benutzten Texte, die besuchten Ortschaften usw.
}

Die alten handschriftlichen Urkunden werden mit römischen Ziffern', die Texte in moderner Mundart mit grolsen lateinischen Buchstaben bezeichnet, in folgender Weise:

I. Cartulaire d'Anione'.

II. Cartulaive de Gellone?.

III. Cartulaire des Guilhems de Montpellier?.

IV. u. V. Rechnungsbücher der Konsuln (prohomes) der Stadt Aniane aus den Jahren $1373 / 74$; 2 wei Teile ${ }^{3}$, verschiedenen Formats und von verschiedenen Schreibern herrührend, sind zusammengeheftet, das Papier ist namentlich an den Rändern durch Feuchtigkeit stark angegriffen. Ein Titel fehlt, auch ist das Ganze noch nicht in eine bestimmte Reihe eingeordnet worden. Dies Dokumeut, das einzige, das ich in den Archives départementales in Montpellier gefunden habe 4 , ist nach seinem Umfang wie in sprachlicher Hinsicht das wichtigste.

Die folgenden Texte entstammen den Archizes communales der mairie z.u Aniane.

VI. Rechnungsbuch des Marc Mylhau, prodome rector, aus den Jahren 1555-56 (Serie $C C)^{5}$.

VII. ${ }_{n}$ Recueil de quelques actes du régime et des dellibirations consulaires de la ville d'Aniane, commençant en l'an $1528^{\circ}$ et finissant en l'an $1596^{\prime \prime}$ (Serie $B B$, Nr. 5 ; vach 1572 ist alles in französischer Sprache geschrieben).

VIII. Tailles pour "la monition et entretenement" de la garnison militaire "pour tenir ladite ville de Anyane en obeyssanie du Roy et de sa mageste" (Serie $C C)^{s}$.

IX. "Recueil d'actes consulaires ... commençant en 1447, finissant en 1522 " (Serie $B B$, Nr. 2)".

X. Derselbe Titel (Serie $B B$, Nr. 3$)^{5}$.

Bem. VI-X werden $\mathrm{Dach} Z$ eilen angeführt.

1 Eine genaue Chronologie befindet sich im Anhang I.

${ }^{2} \mathrm{~S}$. Literaturverzeichnis unter B. "Lokales".

3 IV zählt etwa 60, V etwa 20 Seiten.

- Alle andern sind lat. geschrieben.

5 Nur ausgewählte Abschnitte. 
Hierzu kominen an moderned Texten':

A: IV f. $15 v^{\circ}$ von Ane.c in die moderne Mundart übertragen?.

$B$, Nr. I-6b: Kurze Geschichten und Lieder, an Ort und Stelle aufgenommen.

C: Gedruckte "couplets" ans einem Konzertprogramm".

$D$ : Konjugationsmuster - zunächst unaufgefordert - hergestellt von Ane. P.

Phon. I-28 verweist auf die im Vorwort erwähnten Phonogramme.

Die besuchten Orte werden unter folgenden Abkürzungen zitiert:

\begin{tabular}{|c|c|c|c|}
\hline $\begin{array}{l}\text { ne.: } \\
\text { GD.; }\end{array}$ & $\begin{array}{l}\text { Aniane, } \\
\text { Saint-Guilhelm-le-Déseri } \\
\text { (Gellone), }\end{array}$ & $\begin{array}{l}\text { LaB.: } \\
\text { Ggn.: } \\
\text { SJF.: }\end{array}$ & $\begin{array}{l}\text { La Boissière, } \\
\text { Gignac, } \\
\text { Saint-Fean-de-Fos, }\end{array}$ \\
\hline & Puéchabon, & LaV.: & La Vacquerie. \\
\hline
\end{tabular}

Mp. bedeutet Montpellier.

Die hinter die Ortsnamen als Exponenten gesetzten kleinen Buchstaben bezeichnen die Gefragten, deren Personalien aus dem Anhang II zu ersehen sind.

Bem.: Ohne näbere Ortsangabe aufgerührte Formen kommen in allen sieben Ortschaften vor.

1 Beigefügt im Anhang II.

2 Ich bin mir wohl bewufst, dars dieser "Übersetzung " nicht der Wert eines lebendigen Spracbzeugnisses zukommen kann; es sollte vor allem ein Vergleich zwischen alter und moderner Mundart ermöglicht werden. konnte.

- Ein Heftchen, das seines Umfanges wegen nicht abgedruckt werden 